\title{
Impacts of offshore wind farm construction on harbour porpoises: acoustic monitoring of echo- location activity using porpoise detectors (T-PODs)
}

\author{
J. Carstensen ${ }^{1, *}$, O. D. Henriksen ${ }^{2}$, J. Teilmann ${ }^{1}$ \\ ${ }^{1}$ National Environmental Research Institute, Denmark, Frederiksborgvej 399, PO Box 358, 4000 Roskilde, Denmark \\ ${ }^{2}$ Present address: Oluf.dk, Stavnsbjerg Allé 55, 2730 Herlev, Denmark
}

\begin{abstract}
Offshore wind farming is a new emerging technology in the field of renewable energies. This study investigates the potential impact of the construction of one of the first major, offshore wind farms (>100 MW) on harbour porpoises Phocoena phocoena by means of acoustic porpoise detectors (T-PODs) monitoring porpoise echolocation activity. The monitoring program was established as a modified BACI (before, after, control, impact) design, with 6 monitoring stations equally distributed between the impact area and a nearby reference area. Mean waiting times, defined as the period between 2 consecutive encounters of echolocation activity, increased from $6 \mathrm{~h}$ in the baseline period to $3 \mathrm{~d}$ in the wind farm area during the construction. This increase was 6 times larger than changes observed in the reference area. One specific construction activity, involving the ramming and vibration of steel sheet piles into the seabed, was associated with an additional significant increase in waiting time of 4 to $41 \mathrm{~h}$, in both the construction and reference areas. Assuming that echolocation activity is related to harbour porpoise density, the analysis shows that their habitat-use changed substantially, with the porpoises leaving the construction area of the offshore wind farm. Acoustic monitoring from fixed positions provides data with a high temporal resolution, but low spatial resolution, which can be analysed at a variety of scales, and can be applied to harbour porpoises and other echolocating cetaceans.
\end{abstract}

KEY WORDS: Acoustic monitoring · BACI design · Echolocation · Environmental impact · Assessment $\cdot$ Harbour porpoise $\cdot$ Offshore wind farm $\cdot$ Porpoise detector $\cdot$ T-POD

\section{INTRODUCTION}

Offshore wind power is a rapidly expanding industry in Northern Europe, where several large offshore wind farms are under construction in nearshore waters, many having high densities of marine mammals. The construction and operation of offshore wind farms are disturbing the marine environment, and as such pose a potential threat to marine mammal habitats. In particular, shallow areas are believed to be important to the harbour porpoises Phocoena phocoena for calving and nursing (Koschinski 2002). The largest offshore wind farms today consist of up to 80 wind turbines covering some 20 to $30 \mathrm{~km}^{2}$. Foundations are either steel monopiles driven into the seabed with large pile drivers, or concrete gravitational foundations placed on pebble cushion layers. The major disturbances to marine mammals arising from the construction are noise from ramming and other building activities, boats and barges, whirled-up bottom sediments, and destruction of bottom flora and fauna. Hitherto, the impacts of offshore construction work on harbour porpoises or other small cetaceans have not been studied in detail. Given the extensive plans for expanding the offshore wind energy sector, it is important to know the effect of single wind farms as well as the cumulative effect of several wind farms within the range of each marine mammal population.

In 2002 and 2003, the Nysted Offshore Wind Farm was constructed in a coastal shallow area (between 6 


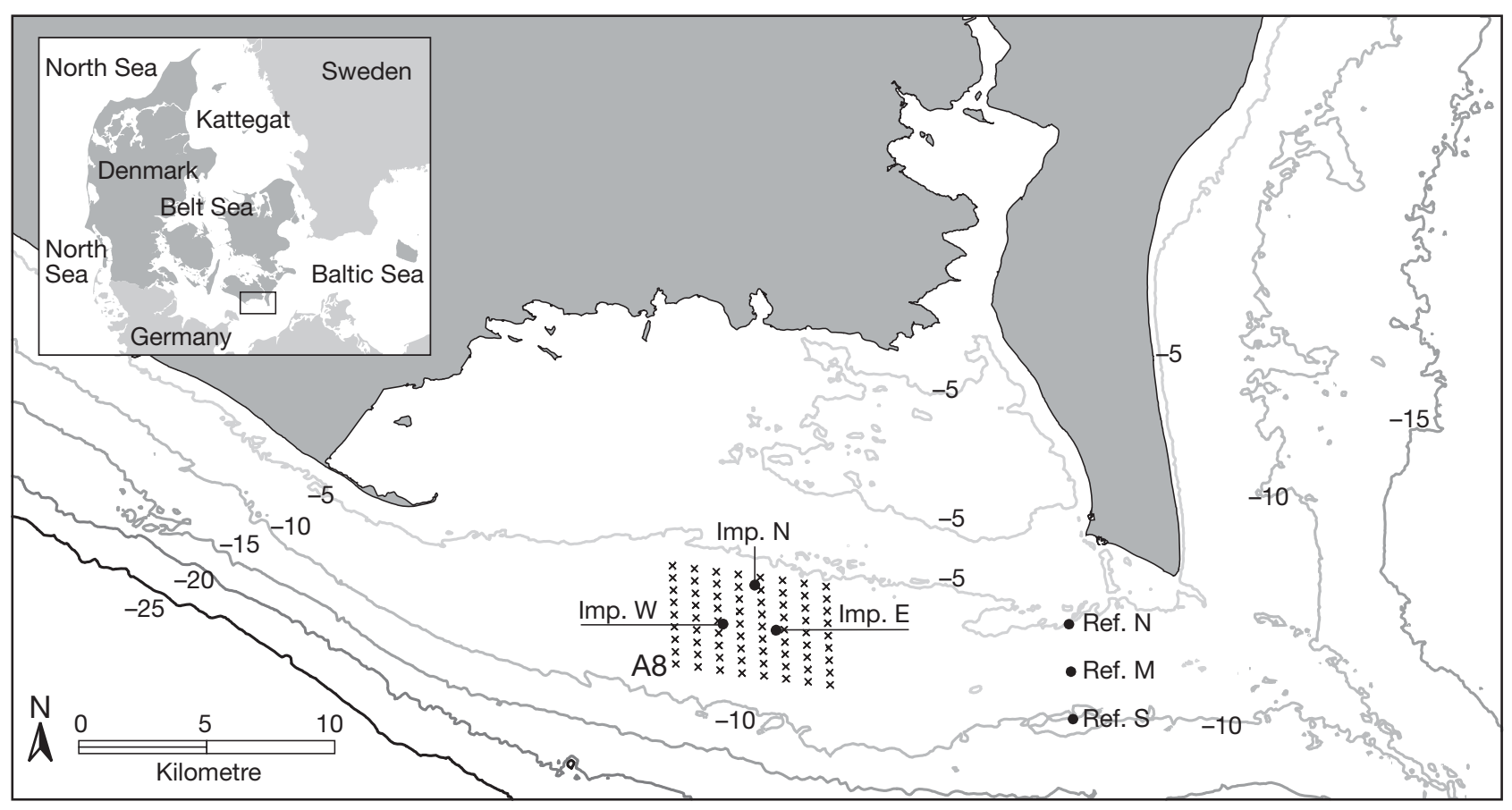

Fig. 1. Nysted Offshore Wind Farm in the western part of the Baltic Sea. The 72 wind turbines $(\mathbf{x})$ are placed in a $8 \times 9$ grid. Foundation A8 (southwestern corner), where the sediments were stabilised with steel sheet piles, is located in the southwestern corner of the wind farm. $(\bullet)$ Positions of porpoise detector (T-POD) deployments (Imp. W, E, N = 3 stations examined in impact area, Ref. N, M, S = 3 stations in reference area). Depth contours (m) are shown

and $9.5 \mathrm{~m} \mathrm{depth)} \mathrm{in} \mathrm{the} \mathrm{Danish} \mathrm{part} \mathrm{of} \mathrm{the} \mathrm{western}$ Baltic Sea $54^{\circ} 30^{\prime} \mathrm{N}, 11^{\circ} 40^{\prime} \mathrm{E}$ (Fig. 1). The sea floor consists of glacial depositions made of sand/silt with scattered stones. The water is brackish, and salinity varies with the surface outflow from the Baltic Sea and more saline water intrusion from the North Sea through the Kattegat and the Belt Sea. Tidal amplitude is less than $0.5 \mathrm{~m}$ but strong winds may change water depth by an additional 1 to $2 \mathrm{~m}$. In a $8 \times 9$ grid covering a total of ca. $24 \mathrm{~km}^{2} 72$ wind turbines (2.2 MW each) with concrete gravitational foundations placed on pebble cushion layers, were constructed (Fig. 1).

The only dedicated surveys for harbour porpoises in the western Baltic area were carried out during the summers of 1991, 1992, and 1994 about $30 \mathrm{~km}$ west of the wind farm area, where an average density of 0.10 porpoises $\mathrm{km}^{-2}$ was found (Heide-Jørgensen et al. 1992, 1993, Hammond et al. 2002). Hence, the wind farm area is located between a relatively high density area including the Kattegat and the Great Belt (0.73 porpoises $\mathrm{km}^{-2}$, Hammond et al. 2002) and the low density Baltic Proper with $<0.01$ porpoises $\mathrm{km}^{-2}$ (Koschinski 2002). In fact, the highest density of harbour porpoises (4.9 porpoises $\mathrm{km}^{-2}$ ) for Europe was reported in a small-scale study in the Belt Sea located about $100 \mathrm{~km}$ from the wind farm area (Teilmann 2003). Harbour porpoises were regularly seen throughout the year during aerial bird surveys conducted in the wind farm area before the construction work started (Bach et al. 2000). Satellite tracking of 52 harbour porpoises in the inner Danish waters during 1997 to 2002 has shown that the wind farm region is regularly visited for short periods at a time, but that the normal harbour porpoise home ranges are several orders of magnitude larger than the wind farm area (Teilmann et al. 2004). The harbour porpoises in the western part of the Baltic Sea are most probably part of a greater population including the Belt Sea and the Kattegat (Teilmann et al. 2004).

Harbour porpoise monitoring has traditionally been carried out by means of shipboard surveys to calculate area- and time-specific densities. Because of the few visual observations during pilot surveys in the area, it was argued that the statistical power of this method would be low (Bach et al. 2000). Instead, we have employed a novel device, the T-POD (The POrpoise Detector) a self-contained acoustic data logger (Thomsen et al. 2005), which monitors the harbour porpoise echolocation activity continuously at fixed positions. The T-POD was chosen for this impact study, assuming that echolocation activity was related to harbour porpoise density, as suggested by the study of Koschinski et al. (2003), because it provided a wealth of data at a reasonable cost.

The objective of the present study was to assess and document the impact of the construction of the Nysted 
Offshore Wind Farm on harbour porpoise density by describing (1) changes in harbour porpoise echolocation activity related to the whole construction period (medium-term response), and (2) changes in harbour porpoise echolocation activity related to steel sheet pile driving/vibration at a single wind turbine foundation (short-term response). Long-term responses to the operation of the wind farm will be investigated in the coming years.

\section{MATERIALS AND METHODS}

The construction of the Nysted Offshore Wind Farm began in mid-June 2002 and continued until the wind farm was put into operation on 1 December 2003. Main activities included excavation for, positioning and ballast-filling of concrete foundations (June 2002 to June 2003), mounting of wind turbines (May to July 2003), and digging, laying and covering of the connecting power grid (August 2002 to November 2003). Around 1 of the 72 foundations (A8, Fig. 1), the seabed had to be stabilised with steel sheet piles that were driven into the sediments using a pile driver and a bargemounted vibrator. This activity occurred intermittently, with either the vibrator or the pile driver in continuous operation for periods of 1.5 to $10 \mathrm{~h}$ for a total of $25 \mathrm{~d}$ from 26 August to 20 November 2002. The start and ending of the ramming/vibration activity was recorded exactly to the minute. Acoustic harassment devices (harbour porpoise pinger and seal scarer) were employed near $(<200 \mathrm{~m})$ this foundation from $30 \mathrm{~min}$ before and up to the end of the ramming/vibration activity. Ambient noise levels from construction activities and harassment devices were not measured. Preliminary activities in the impact area up to 1 July 2002 were considered negligible and at least not substantially different from the normal boating activity, whereas construction activities from July 2002 to November 2003 were hypothesised to have a potential impact on harbour porpoises Phocoena phocoena.

T-POD monitoring. The T-POD is a self-contained submersible computer and hydrophone that recognises and logs echolocation clicks from porpoises and dolphins (Thomsen et al. 2005). Clicks (click duration and repetition rate) within the appropriate frequency bands of the harbour porpoise echolocation spectrum are logged and can be retrieved from the T-POD to a PC during maintenance visits. A software program accompanies the T-POD with an algorithm for detecting the characteristic harbour porpoise click-trains, while removing noise from boat sonars or other short duration click-like sounds having the same spectral properties as echolocation clicks (see www.chelonia. demon.co.uk for more details). It has a spatial cover- age up to a radial distance of $170 \mathrm{~m}$ (Koschinski et al. 2003).

The porpoise echolocation activity was monitored by deploying T-PODs at 3 positions within the wind farm impact area (Imp. W, N, E) and at 3 positions in a reference area $10 \mathrm{~km}$ east of the wind farm (Ref. N, M, S; Fig. 1). No prior information existed on the specific porpoise densities in the impact and reference areas, and the reference area was chosen to reflect similar bathymetry, bottom features and distance from shore as the impact area. In the impact area, the T-PODs were deployed in a triangle $1.9 \mathrm{~km}$ apart to cover the central part of the wind farm area, whereas the reference area was chosen as a N-S transect, with $1.9 \mathrm{~km}$ between deployments to avoid interference with shipping lanes (Fig. 1). Distances from Foundation A8 to the deployment sites were 2.1, 4.0 and $4.0 \mathrm{~km}$ to Imp. W, N and E, respectively, and 15.3, 15.4 and $15.7 \mathrm{~km}$ to Ref. N, M and S, respectively.

The T-PODs were moored with a concrete block and a small anchor for easy recovery and maintenance of the device (Fig. 2); they were retrieved, the batteries changed $(6 \times 3.6 \mathrm{~V}$ lithium D-cell batteries $)$ and the data saved on a laptop approximately every $60 \mathrm{~d}$. Technical problems resulted in some data loss (gaps in the time series), but T-PODs were in operation both before and during construction at all 6 positions. The T-POD data used in this study was separated into 2 distinct periods: a baseline period (November 2001 to June 2002) and a construction period (July 2002 to November 2003) that included the construction activities that could potentially affect the harbour porpoises in the area. Some T-PODs were lost and replaced with new ones at 3 positions ( 1 in the impact area and 2 in the reference area) during the course of the construction period. Each individual T-POD was deployed at the same station during the entire study to avoid con-

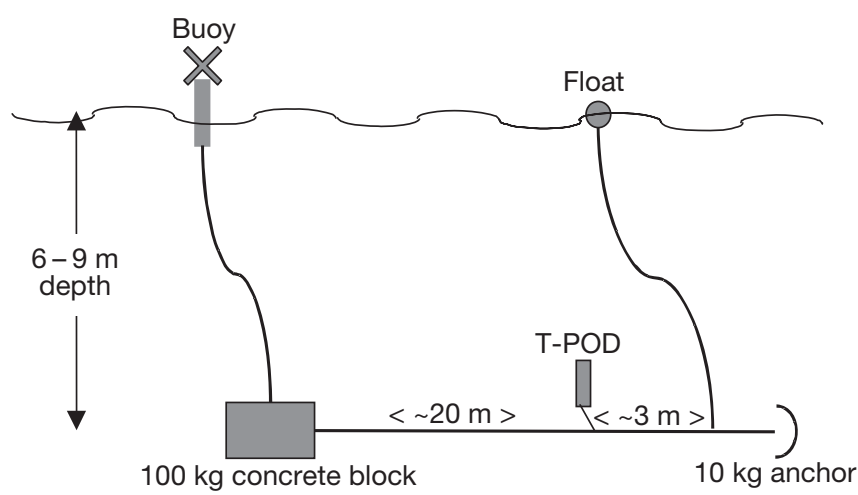

Fig. 2. T-PODs deployment. Anchor and buoy are connected to concrete block with $12 \mathrm{~mm}$ stainless-steel strengthened ropes. In shallow and calm waters T-POD can be retrieved by hand, should the small float be lost; the T-POD must be retrieved by diver or with a crane 
founding instrument variation with temporal shift from baseline to construction, and fortunately, the T-POD replacements did not coincide with this investigated change.

All T-PODs used in this study were Version 1, equipped with external transducers and equivalent configuration. For each T-POD, all 6 channels/scans were set to the identical default values for harbour porpoises: (1) Filter $\mathrm{A}=130 \mathrm{kHz}_{\text {; }}$ (2) Filter $\mathrm{B}=90 \mathrm{kHz}$; (3) ratio = 5; (4) Q-value for Filter $A=5$; (5) Q-value for Filter $B=18$; (6) sensitivity threshold $=0$; (7) maximum number of clicks $=240$ clicks $9 \mathrm{~s}^{-1}$; (8) minimum click duration = $10 \mu \mathrm{s}$. After retrieving the data from the T-PODs, harbour porpoise click-trains were identified using the 'low probability cetacean train' algorithm of the T-POD software, and the number of clicks $\min ^{-1}$ was exported for subsequent data analysis (www.chelonia. demon.co.uk).

Statistical analysis. Porpoise click-trains were frequently observed as short distinct periods of high echolocation activity separated by longer periods with no activity (silent period). The exported time series of clicks per minute were converted into 'porpoise encounters', defined as a series of harbour porpoise clicks of any length when silent periods $<10 \mathrm{~min}$, a value chosen from examination of time series plots of data. Click series separated by silent periods of $>10$ min were consequently defined as 2 separate encounters. The period between harbour porpoise encounters was denoted 'waiting time' and used as a proxy indicator for harbour porpoise density in the statistical analysis. It should be stressed that because of differences in deployments at the stations and loss of T-PODs the data available for the statistical analysis was balanced in neither space nor time.

Waiting times were analysed according to a modified BACI design (Green 1979) that included station-specific, T-POD specific, and seasonal variation. The BACI (before, after, control, impact) design can be viewed as a variant of the split-plot design, since the 2 levels of the treatment (baseline versus construction) were not observed simultaneously. In the present design, the month of the observation was included as an additional blocking factor (split-split-plot design) to account for seasonal variation, such that waiting times were compared over the same months in progressive years. This is valid, because there was replication of months within the $2 \mathrm{yr}$ monitoring period. The model for the waiting times $\left(Y_{t}\right)$, after subtracting $10 \mathrm{~min}$ and logtransformation, was: where $\mu$ is the overall mean, $a=$ area has 2 levels (control, impact), $p=$ period has 2 levels (baseline, construction), $m=$ month has 11 levels (February to December), $S=$ station has 6 levels (Imp. N, W and $E_{\text {; }}$ Ref. N, M and S), and T= T-POD has 9 levels (T-POD identification number $=7,14,17,43,47,48,56,67,71$ ). There were 18 different plots, denoted by $R=$ plot in Eq. (1), where sampling was random within area, station and T-POD. Subscript letters in Eq. (1) are indices for different levels of the effects in the model. The model in Eq. (1) has 4 fixed effects (indicated by lowercase letters), where 'area' describes the spatial variation between control and impact area, 'month' describes the seasonal variation by means of monthly values and 'period' describes the stepwise change at the onset of the construction work, whereas 'area $\times$ period' describes a difference in the stepwise change between the 2 areas. The random effects of the model (indicated by uppercase letters) were 'station(area)' describing the station-specific variation nested within the 2 areas, 'tpod(area station)' describing the T-POD specific variation within the 3 stations where the equipment was replaced during construction, 'plot' describing the variation between months of monitoring, and 24 interactions. The significance of the random effects was tested and insignificant random effects were pooled with the residual variation.

The interaction area $\times$ period, also referred to as the BACI effect, therefore described a stepwise change in the impact area different from that in the reference area. Marginal means for the different factors of the model were calculated and back-transformed to mean values on the original scale using the moment's transformations of the log-transform (p. 285 in McCullagh \& Nelder 1989) and adding the $10 \mathrm{~min}$ threshold. The BACI effect, having 1 numerator degree of freedom, was also calculated explicitly as a contrast of the marginal means for the 4 combinations of area and period, and

$\exp ($ BACI contrast $)=\frac{E[\text { Imp., constr. }]}{E \text { [Imp., basel. }]} \times \frac{E \text { [Ref., basel. }]}{E \text { [Ref., constr. }]}$

where $E[]$ denotes the expectation values. Thus, the exponential of the contrast described the relative change from the baseline to the construction period in the impact area relative to the reference area.

The model in Eq. (1) can be formulated within the framework of general, linear, mixed models

$$
\begin{aligned}
& Y_{t(i j k l m n)}=\mu+\underbrace{R_{i}+p_{j}+R P_{i j}}_{\text {whole-plot }}+\underbrace{m_{k}+R M_{i k}+P M_{j k}+R P M_{i j k}}_{\text {split-plot }}+\underbrace{a_{1}+R A_{i l}+p a_{j l}+R P A_{i j l}+M A_{k l}+R M A_{i k l}+P M A_{j k l}+R P M A_{i j k l}}_{\text {split-split-plot(area) }} \\
& +\underbrace{S_{m(l)}+R S_{i m(l)}+P S_{j m(l)}+R P S_{i j m(l)}+M S_{k m(l)}+R M S_{i k m(l)}+P M S_{j k m(l)}+R P M S_{i j k m(l)}}_{\text {split-split-plot(station) }} \\
& +\underbrace{T_{n(l m)}+R T_{i n(l m)}+P T_{j n(l m)}+R P T_{i j n(l m)}+M T_{k n(l m)}+R M T_{i k n(l m)}+P M T_{j k n(l m)}+R P M T_{i j k n(l m)}}_{\text {split-split-plot(t-pod) }}+\varepsilon_{t(i j k l m n)}
\end{aligned}
$$




$$
\mathbf{Y}=\mathbf{X} \boldsymbol{\beta}+\mathbf{Z u}+\mathbf{e}
$$

where $\mathbf{Y}$ is the vector of observations, $\mathbf{X}$ is the design matrix for the fixed effects, $\boldsymbol{\beta}$ is the vector of parameters for the fixed effects, $\mathbf{Z}$ is the design matrix for the random effects, $\mathbf{u}$ is the vector of random effects with covariance matrix $\mathbf{G}$, and $\mathbf{e}$ is the vector of the residuals with the covariance matrix $\mathbf{R}$. The temporal variation in waiting times was assumed to follow an overall, fixed, seasonal pattern described by monthly means, but fluctuations in the harbour porpoise density in the region on a shorter time scale may potentially give rise to serial correlations in the observations. For example, if a short waiting time is observed, the next waiting time is likely to be short as well. In order to account for any autocorrelation in the residuals, we formulated a covariance structure for the residuals $\left(\mathbf{R} \neq \sigma^{2} \mathbf{I}\right)$ by means of an ARMA(1,1)-process (Chatfield 1984) subject to waiting times observed within separate deployments, i.e. complete independence was assumed across gaps in the time series. Thus, this model included an extension to the general linear theory (e.g. McCullagh \& Nelder 1989) by mixing fixed and random effects (McCulloch \& Searle 2001).

In the BACI design, the overall seasonal variation was assumed to be identical for the 2 areas, since they were located relatively close to each other and with similar bottom and depth properties. This basic assumption was investigated with the following model employed on baseline data only:

$$
Y_{t(\mathrm{klm})}=\mu+m_{k}+a_{l}+m a_{k l}+S_{m(l)}+M S_{k m(l)}+\varepsilon_{t(k l m)}
$$

where the first 2 factors of the model have the same interpretation as in Eq. (1), and the interaction area $\times$ month describes systematic differences in the seasonal variation of the 2 areas; 2 random effects, station(area) and station(area) $\times$ month, were also included. None of the T-PODs were replaced during baseline, and therefore the effect T-POD (area station) was completely confounded with station(area). There was no replication of months for the baseline data and therefore this analysis was carried out using a factorial block design. If the interaction area $\times$ month in Eq. (4) is significant, temporal variations in harbour porpoise density may not be comparable for the 2 areas, jeopardising the BACI design. Therefore, we examined the consequences for the interaction area $\times$ month by eliminating data from individual stations separately. The ARMA $(1,1)$ covariance structure of $\mathbf{R}$ was also applied to this model (Eq. 4).

The T-POD-specific variation was nested within stations, and similarly the station-specific variation was nested within areas in Eq. (1). This implied that the factors area and station(area) were a combination of spatial variation and T-POD-specific sensitivity. How- ever, the interaction (area $\times$ period) remained unaffected by this, because the T-PODs were not interchanged between stations during the study period and consequently the testing for a potential effect of the construction work in the impact area was not biased by differences in T-POD sensitivity. The hierarchical structure for area, station and T-POD-specific variation was chosen in favour of crossing the T-POD-specific variation with the spatial variation, because shifting the T-PODs between stations would require additional substantial effort, with a risk of the T-POD-specific variation being partly or even totally confounded with the BACI effect (area $\times$ period).

To investigate the short-term effect of ramming/ vibration activity in the period from 25 August to 20 November 2002, the first and second encounter after this specific construction activity had ceased were identified, and the corresponding waiting times prior to these encounters were analysed to investigate if waiting times (first and second separately) following ramming/vibration activity were different. For each station, the distribution of first waiting times was compared to the distribution of all other observations during this specific period, and similarly, the distribution of second waiting times was compared to the distribution of all observations except first and second waiting times. For this analysis, the correlation parameters of the ARMA(1,1)-process in the covariance structure $\mathbf{R}$ were not estimated, but set to the values obtained from analysing all data according to Eq. (1), since the number of observations in this specific period was limited. In order to account for different magnitudes of variation between first, second and other waiting times, different variance parameters in $\mathbf{R}$ for these 3 categories were estimated, but the correlation parameters between observations in time were fixed.

The statistical analyses were carried out within the framework of mixed linear models (Littell et al. 1996, McCulloch \& Searle 2001) by means of PROC MIXED in the SAS system. Statistical testing for fixed effects ( $F$-test with Satterthwaite approximation for denominator degrees of freedom) and random effects (Wald $Z$ ) were carried out at a $5 \%$ significance level (Littell et al. 1996). The F-test for fixed effects was partial, i.e. considering the specific contribution of the given effect in addition to all other factors.

\section{RESULTS}

The 9 T-PODs used in this study were deployed at the 6 stations for a total of $1617 \mathrm{~d}$, with approximately $47 \%$ more deployment days in the impact area than in the reference area (Table 1). During the days of deployment, 3704 waiting times were recorded at the 
Table 1. Logging period showing number of days deployed, number of observations (n) and average waiting time for deployed T-PODs. Periods listed were combined of several deployments including long periods without data

\begin{tabular}{|c|c|c|c|c|c|c|c|}
\hline \multirow[t]{2}{*}{ Stn } & \multirow{2}{*}{$\begin{array}{c}\text { T-POD } \\
\text { no. }\end{array}$} & \multirow{2}{*}{$\begin{array}{l}\text { Logging period } \\
\text { (d/mo/yr) }\end{array}$} & \multirow{2}{*}{$\begin{array}{c}\text { Days } \\
\text { deployed }\end{array}$} & \multicolumn{2}{|c|}{ - Baseline - } & \multicolumn{2}{|c|}{ Construction - } \\
\hline & & & & $\mathrm{n}$ & Avg. (min) & $\mathrm{n}$ & Avg. (min) \\
\hline \multicolumn{8}{|c|}{ Impact area } \\
\hline Imp. N & T-POD47 & $8 / 4 / 2002-8 / 10 / 2003$ & 216 & 173 & 320 & 129 & 1707 \\
\hline Imp. W & T-POD56 & $14 / 11 / 2001-30 / 11 / 2003$ & 402 & 509 & 233 & 319 & 1363 \\
\hline \multirow[t]{2}{*}{ Imp. E } & T-POD67 & $8 / 4 / 2002-8 / 8 / 2002$ & 123 & 545 & 215 & 117 & 465 \\
\hline & T-POD71 & $5 / 2 / 2003-30 / 11 / 2003$ & 222 & & & 66 & 4353 \\
\hline Overall & & & 963 & 1227 & 237 & 631 & 1580 \\
\hline \multicolumn{8}{|c|}{ Reference area } \\
\hline \multirow[t]{2}{*}{ Ref. N } & T-POD14 & $3 / 5 / 2002-23 / 9 / 2002$ & 126 & 138 & 599 & 127 & 709 \\
\hline & T-POD17 & $12 / 8 / 2003-1 / 9 / 2003$ & 21 & & & 3 & 7827 \\
\hline Ref. M & T-POD43 & $8 / 4 / 2002-30 / 11 / 2003$ & 345 & 221 & 406 & 807 & 485 \\
\hline \multirow[t]{2}{*}{ Ref. S } & T-POD48 & $4 / 4 / 2002-5 / 4 / 2003$ & 117 & 141 & 311 & 101 & 1117 \\
\hline & T-POD7 & $7 / 10 / 2003-30 / 11 / 2003$ & 45 & & & 308 & 199 \\
\hline Overall & & & 654 & 500 & 433 & 1346 & 504 \\
\hline
\end{tabular}

6 stations with an almost equal number of observations before $(\mathrm{n}=1727)$ and during $(\mathrm{n}=1977)$ construction, although the T-PODs were deployed for considerably longer periods during the construction. The average waiting time increased at all stations from the baseline to the construction period, but the increase was considerably larger in the impact area (Table 1). The monitoring stations were not in continuous operation throughout the entire study period, but the time series from the different stations were overlapping to comprise combined time series for both the reference and the impact area spanning both the baseline and the construction periods. Consequently, data from the different stations were compared through the assumption of a common seasonal pattern.

The change in harbour porpoise echolocation activity in the impact area was also visible from time series plots (Fig. 3), whereby the observed waiting times never exceeded $2 \mathrm{~d}$ in the baseline period, but numerous encounters were separated by more than $1 \mathrm{wk}(\sim 10080 \mathrm{~min})$ during the construction period. In fact, at Stn Imp. W, no harbour porpoise click-train was recorded over a 38 d period from 25 February to 4 April 2003. Waiting times were generally longer in the winter period and shorter in the summer period, during both the baseline and construction periods (Fig. 3). The replacement of T-PODs at 3 stations did not introduce any clearly visible systematic shift in the waiting time levels (Fig. 3).

Investigating the spatial and temporal variations of the waiting times using baseline data only revealed that the area-specific monthly means were not common to both the control and impact area. The significance of area $\times$ month in Eq. (4) was potentially due to data from 1 of 3 stations (Imp. E, Ref. N, or Ref. S), but excluding data from Ref. $\mathrm{N}$ yielded the most similar seasonal means for the 2 areas (highest p-value) and the least residual variation (Table 2). Thus, the assumption of common temporal variations in harbour porpoise echolocation activity throughout the investigated area was not compromised, provided that data from Ref. $\mathrm{N}$ were excluded from the baseline data analysis. Removing the least significant factor, area $\times$ month, from the model (Eq. 4) of the baseline data after excluding Stn Ref. N showed a significant seasonal variation $\left(F_{4,56.7}=11.60 ; \mathrm{p}<0.0001\right)$, but no significant variation between the reference and impact areas $\left(F_{1,2.97}=2.00 ; \mathrm{p}=0.2531\right)$. None of the random effects were significant $\left(\sigma^{2}\right.$ station(area) $=0.1065 ; Z=0.97$; $\mathrm{p}=0.1657$ and $\sigma_{\text {station(area) } \times \text { month }}^{2}=0$ ) and they were much smaller than the residual variation $\left(\sigma^{2}=2.2789\right.$; $Z=26.45 ; \mathrm{p}<0.0001)$.

Table 2. Phocoena phocoena. Analysis of area-specific monthly means for waiting times according to Eq. (4), using baseline data only, for all stations and excluding (excl.) individual stations. Statistics for factor area $\times$ month are shown only. Denominator degrees of freedom (Den df) computed by Satterthwaite's approximation (Littell et al. 1996)

\begin{tabular}{|c|c|c|c|c|c|}
\hline \multirow{2}{*}{$\begin{array}{l}\text { Data used } \\
\text { in model }\end{array}$} & \multicolumn{4}{|c|}{ area $\times$ month statistics } & \multirow{2}{*}{$\begin{array}{l}\text { Residual } \\
\text { variance }\end{array}$} \\
\hline & df & Den df & $F$ & $\mathrm{p}$ & \\
\hline All stations & 2 & 65.0 & 3.88 & 0.0257 & 2.3556 \\
\hline Excl. Imp. N & 2 & 55.9 & 3.82 & 0.0279 & 2.3998 \\
\hline Excl. Imp. W & 2 & 47.1 & 3.57 & 0.0359 & 2.3542 \\
\hline Excl. Imp. $E^{a}$ & 2 & 39.9 & 2.63 & 0.0843 & 2.4011 \\
\hline Excl. Ref. N & 2 & 62.0 & 2.11 & 0.1294 & 2.2757 \\
\hline Excl. Ref. M & 2 & 36.7 & 4.91 & 0.0128 & 2.3945 \\
\hline Excl. Ref. S & 2 & 65.9 & 2.67 & 0.0765 & 2.3359 \\
\hline
\end{tabular}



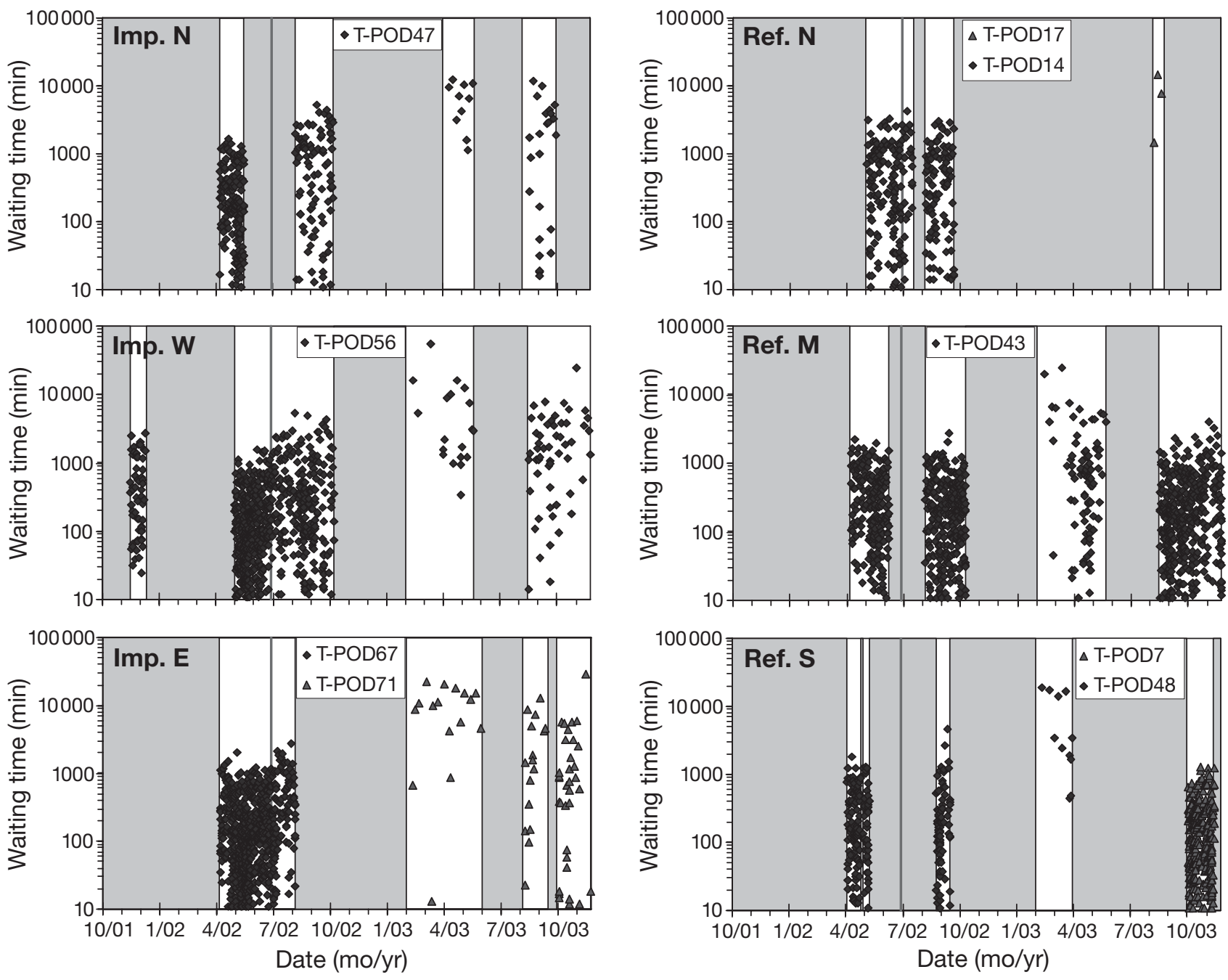

Fig. 3. Phocoena phocoena. Waiting times between harbour porpoise encounters in impact area (Stns Imp. N, W, E) and reference area (Stns Ref. N, M, S). Grey shading: periods with no T-POD deployments; vertical lines indicate change from baseline to construction period. Note logarithmic scale

\section{BACI analysis}

Except for 3 random (although not significant) effects, the majority of the random effect variances for the full model in Eq. (1) were zero. After pooling those effects with zero variance contribution with the residual variation, the 3 variance-contributing random effects were still insignificant (Table 3), and consequently, all random effects were pooled with the residual variation.

The fixed factors in the BACI analysis (Eq. 1) were all significant (Table 4). In the reference area, the waiting times almost doubled from the baseline to the construction period (from about 9 to $20 \mathrm{~h}$ ), whereas waiting times in the impact area increased by more than 1 order of magnitude (from about $5.5 \mathrm{~h}$ to $3 \mathrm{~d})$. Although the waiting times be- came longer during the construction in both reference and impact areas, the increase in the impact area was more than 6 times larger (BACI contrast of 1.8005) than in the reference area. In the baseline period, harbour porpoise encounters were more frequent in the impact area, but after construction began, the refer-

Table 3. Variance estimates and test for random effects in BACI (before, after, control, impact) analysis after contributing effects of zero variance have been pooled with residual variation

\begin{tabular}{|lccrr|}
\hline $\begin{array}{l}\text { Variance } \\
\text { contributing effect }\end{array}$ & Estimate & SE & $\begin{array}{r}\text { Wald's } \\
Z \text {-test }\end{array}$ & $\mathrm{p}$ \\
\hline Period $\times$ Month $\left(P M_{j k}\right)$ & 0.7109 & 0.8105 & 0.88 & 0.1902 \\
Plot $\times$ Area $\left(R A_{i l}\right)$ & 0.1126 & 0.1005 & 1.12 & 0.1313 \\
Plot $\times$ Station $\left(R S_{i m(l)}\right)$ & 0.0729 & 0.0562 & 1.30 & 0.0974 \\
Residuals & 2.6208 & 0.0707 & 37.10 & $<0.0001$ \\
\hline
\end{tabular}


Table 4. Phocoena phocoena. BACI analysis of waiting times (3436 observations) between porpoise encounters at Nysted Offshore Wind Farm. Data from Stn Ref. N were not included in analysis. Tests for fixed effects are shown above; marginal means, calculated from parameter estimates and back-transformed to original scale, are shown below

\begin{tabular}{|c|c|c|c|c|}
\hline Factor & df & Den df & $F$ & $\mathrm{p}$ \\
\hline Area & 1 & 36.1 & 7.17 & 0.0111 \\
\hline Month & 10 & 107 & 7.06 & $<0.0001$ \\
\hline Period & 1 & 68.5 & 36.09 & $<0.0001$ \\
\hline Area $\times$ Period & 1 & 41.5 & 35.12 & $<0.0001$ \\
\hline \multicolumn{5}{|c|}{ BACI marginal means } \\
\hline & \multicolumn{2}{|c|}{ Reference } & Impact & Overall \\
\hline Baseline & \multicolumn{2}{|c|}{$542 \mathrm{~min}$} & $337 \mathrm{~min}$ & $427 \mathrm{~min}$ \\
\hline Construction & \multicolumn{2}{|c|}{$1213 \mathrm{~min}$} & $4483 \min$ & $2329 \min$ \\
\hline Overall & \multicolumn{2}{|c|}{$810 \min$} & $1219 \min$ & \\
\hline
\end{tabular}

ence area had the highest (although relatively low) echolocation activity.

The seasonal variation used to compare waiting times across differences in the deployments had a pronounced pattern (Fig. 4), with long waiting times in February and March (means $>1 \mathrm{~d}$ for both areas and periods combined) and shorter waiting times in July to November (means between 1.8 and $5.8 \mathrm{~h}$ for both areas and periods combined). There were no data for January, and the marginal means obtained from Eq. (1) therefore expressed the expectation value for $11 \mathrm{mo}$ only. Long waiting times in February and March combined with relatively fewer deployments resulted in less than 20 observations in total for each of these 2 months, and consequently the monthly mean estimates were more uncertain. There were also few observations from July in the reference area because of the short deployment time.

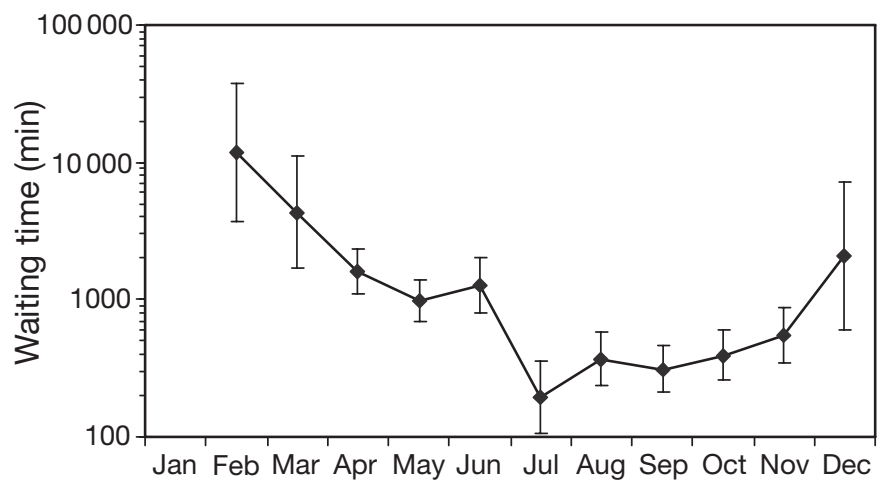

Fig. 4. Phocoena phocoena. Monthly mean ( $\pm 95 \%$ CL) marginal distribution of waiting times after back-transformation. Variations attributable to other significant factors in Eq. (1) have been accounted for by calculating marginal means. Note logarithmic scale
The area- and period-specific marginal means should be interpreted as the expected waiting time over 11 mo (excluding January) in both the baseline and construction periods, and the monthly marginal means should be interpreted as the expected waiting time in both areas combined. Finally, the BACI marginal means (Table 4) should be interpreted as the expected waiting time over 11 mo (excluding January) for the 4 combinations of area $\times$ period. The marginal means of the model were generally higher than the average values (Table 1) because there were considerably more observations during the summer period, with shorter waiting times.

\section{Waiting times after ramming/vibration activity}

In the period with ramming activity, 5 out of the 6 T-PODs were logging harbour porpoise echolocation activity from 25 August to 12 October, and 8.7 to $20.8 \%$ of the observations were identified as first and second waiting times for these stations. First waiting times measured the period elapsed between the first measured clicking bout after a ramming/vibration activity session and the last measured bout, and thus included some time from both before and during the session as well as immediately after. First waiting times were relatively high at all stations in both the impact and reference areas, whereas the second waiting times were on average level (Fig. 5). All 5 stations had a significantly higher first waiting time (Table 5), whereas the second waiting time after ramming/vibration activity was not different from the overall waiting time between encounters at any of the stations during this specific period (Table 6).

Waiting times for the first encounter after ramming activity had ceased increased significantly at all stations by factors of 9.0 for Imp N, 13.9 for Imp W, 9.0 for Ref. N, 3.5 for Ref. M, and 6.1 for Ref. S (Table 5). The first waiting time in the impact area was typically 35 to $50 \mathrm{~h}$ (means for the 2 stations) compared to the 'normal' level of 20 and $10 \mathrm{~h}$ for Imp. $\mathrm{N}$ and $\mathrm{W}$, respectively (Table 5). In the reference area, mean waiting times (excluding first waiting time observations) increased from 17, 7, and $6 \mathrm{~h}$ to 30,11 and $19 \mathrm{~h}$ for the first encounter after ramming activity for Ref. N, M and $\mathrm{S}$, respectively. The increase in the waiting time was longer than the average duration of ramming/vibration activity $(5.5 \mathrm{~h})$, including the deployment of harassment devices, for all stations except Ref. M. The largest increase was observed at Stn Imp. W, the station closest to the site of ramming/vibration, where the first waiting times were $41 \mathrm{~h}$ longer than other waiting times in this specific period of ramming/vibration activity. The analysis of first and second waiting times 

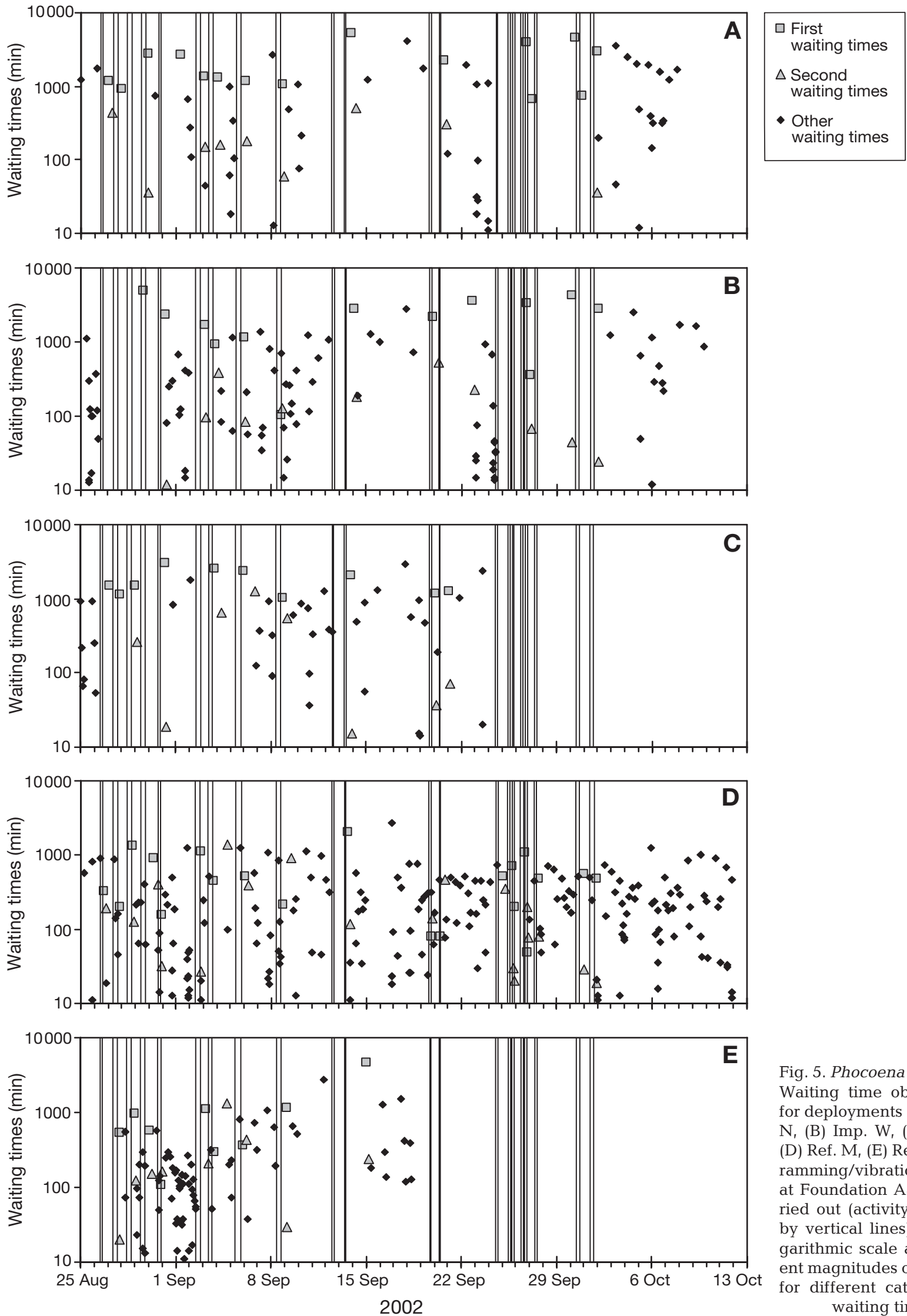

Fig. 5. Phocoena phocoena. Waiting time observations for deployments at (A) Imp. N, (B) Imp. W, (C) Ref. N, (D) Ref. M, (E) Ref. S, when ramming/vibration activity at Foundation A8 was carried out (activity indicated by vertical lines). Note logarithmic scale and different magnitudes of variation for different categories of waiting times 
Table 5. Phocoena phocoena. First waiting times (min) after ramming/vibration activity had ceased versus second and other waiting times (min) from 25 August to 12 October 2002. Distributions of log-transformed data were back-transformed into median and mean waiting times by exponential function and moment transformation, respectively

\begin{tabular}{|c|c|c|c|c|c|c|c|}
\hline \multirow{2}{*}{$\begin{array}{l}\text { Stn } \\
\text { Waiting time }\end{array}$} & \multirow{2}{*}{$\mathrm{n}$} & \multicolumn{4}{|c|}{ - Log-transformed waiting time- } & \multicolumn{2}{|c|}{ Waiting time } \\
\hline & & Mean & Variance & $F$ & $\mathrm{p}$ & Median & Mean \\
\hline \multicolumn{8}{|l|}{ Imp. N } \\
\hline $1 \mathrm{st}$ & 15 & 7.44 & 0.43 & 52.08 & $<0.0001$ & 1708 & 2121 \\
\hline 2nd + other & 57 & 5.24 & 3.61 & & & 199 & 1164 \\
\hline \multicolumn{8}{|l|}{ Imp. W } \\
\hline $1 \mathrm{st}$ & 13 & 7.40 & 1.25 & 52.99 & $<0.0001$ & 1641 & 3062 \\
\hline 2 nd + other & 95 & 4.77 & 3.24 & & & 128 & 604 \\
\hline \multicolumn{8}{|l|}{ Ref. N } \\
\hline $1 \mathrm{st}$ & 10 & 7.40 & 0.15 & 55.09 & $<0.0001$ & 1647 & 1771 \\
\hline 2 nd + other & 47 & 5.21 & 3.41 & & & 193 & 1017 \\
\hline \multicolumn{8}{|l|}{ Ref. M } \\
\hline $1 \mathrm{st}$ & 20 & 5.91 & 1.12 & 22.29 & $<0.0001$ & 377 & 653 \\
\hline 2nd + other & 210 & 4.66 & 2.70 & & & 116 & 420 \\
\hline \multicolumn{8}{|l|}{ Ref. S } \\
\hline 1st & 9 & 6.44 & 1.16 & 20.54 & 0.0007 & 639 & 1133 \\
\hline 2nd + other & 81 & 4.63 & 2.51 & & & 113 & 372 \\
\hline
\end{tabular}

Table 6. Phocoena phocoena. Second waiting times (min) after ramming/vibration activity had ceased versus other waiting times (min) from 25 August to 12 October 2002. Distributions of log-transformed data were back-transformed into median and mean waiting times by exponential function and moment transformation, respectively

\begin{tabular}{|c|c|c|c|c|c|c|c|}
\hline \multirow{2}{*}{$\begin{array}{l}\text { Stn } \\
\text { Waiting time }\end{array}$} & \multirow{2}{*}{$\mathrm{n}$} & \multicolumn{4}{|c|}{ Log-transformed waiting time- } & \multicolumn{2}{|c|}{ Waiting time } \\
\hline & & Mean & Variance & $F$ & $\mathrm{p}$ & Median & Mean \\
\hline \multicolumn{8}{|l|}{$\operatorname{Imp} . \mathrm{N}$} \\
\hline 2nd & 10 & 4.88 & 1.99 & \multirow{2}{*}{0.70} & \multirow{2}{*}{0.4142} & 141 & 364 \\
\hline Other & 47 & 5.32 & 3.98 & & & 215 & 1506 \\
\hline \multicolumn{8}{|l|}{ Imp. W } \\
\hline 2nd & 11 & 4.29 & 2.49 & \multirow{2}{*}{1.11} & \multirow{2}{*}{0.3102} & 83 & 262 \\
\hline Other & 84 & 4.83 & 3.33 & & & 135 & 673 \\
\hline \multicolumn{8}{|l|}{ Ref. N } \\
\hline 2nd & 8 & 4.58 & 4.31 & \multirow{2}{*}{0.93} & \multirow{2}{*}{0.3594} & 107 & 850 \\
\hline Other & 39 & 5.34 & 3.24 & & & 218 & 1059 \\
\hline \multicolumn{8}{|l|}{ Ref. M } \\
\hline 2nd & 19 & 4.61 & 2.35 & \multirow{2}{*}{0.03} & \multirow{2}{*}{0.8634} & 110 & 335 \\
\hline Other & 191 & 4.67 & 2.75 & & & 117 & 433 \\
\hline \multicolumn{8}{|l|}{ Ref. S } \\
\hline 2nd & 9 & 4.88 & 2.19 & \multirow{2}{*}{0.27} & \multirow{2}{*}{0.6121} & 142 & 403 \\
\hline Other & 72 & 4.60 & 2.58 & & & 110 & 372 \\
\hline
\end{tabular}

times because of the limited number of observations. The covariance structure obtained from the BACI analysis (Eq. 1) implied that consecutive waiting times were positively correlated $(\operatorname{lag} 1=0.1870$ and $\operatorname{lag} 2=0.1720)$, with a residual variance of 2.79 for the transformed waiting times, which was similar to the correlations obtained in the analysis of baseline data only (Eq. 4 without area $\times$ month) (lag $1=$ 0.1330 and $\operatorname{lag} 2=0.1070$ ), with a residual variance of 2.28. However, the residual variances of the first waiting times were considerably lower (0.15 to 1.25$)$, whereas the variances of the second and other waiting times had magnitudes ranging from 2.51 to 3.61 (Table 5). These differences had repercussions for the mean backtransform using the moment transformation that included a contribution from the variance of the transformed variable (Tables $5 \& 6$ ). This was most pronounced for Imp. N, where mean levels were almost comparable although the medians differed by 1 order of magnitude.

\section{DISCUSSION}

We have employed a novel technique for monitoring the echolocation activity of harbour porpoises in order to assess the potential impact during construction of an offshore wind farm. Although standard hydrophones have been commonly used for monitoring whales in general (e.g. Au et al. 2004), documented studies using the autonomous T-POD are still few (Cox et al. 2001, Culik et al. 2001, Koschinski et al. 2003). Two T-PODs deployed in an exhibition facility in Kerteminde, Denmark (www.gounderwater.com), logged echolocation activity for about 4 to $9 \%$ of the time in which recordings were made (mean waiting times did not include seasonal variations during the ramming/vibration period from the end of August to the beginning of October, as these months had similar mean levels (Fig. 4).

It was not possible to estimate the entire covariance structure in the analysis of the first and second waiting approx $40 \mathrm{~min}$, encounter duration approx. $10 \mathrm{~min}$; Teilmann et al. 2002) when the 2 captive porpoises were present in the pool, whereas only 3 porpoise encounters were recorded over $2 \mathrm{~d}$ without the captive porpoises present in the pool. These recordings may have originated from a wild porpoise approaching the 
enclosure, which is only separated from the sea by a net (Teilmann et al. 2002). Similar results were obtained with captive porpoises in the Netherlands (Thomsen et al. 2005). A study of wild harbour porpoises in Fortune Channel, Vancouver Island, Canada, showed that $98 \%$ of all visual observations within a distance of $150 \mathrm{~m}$ from a T-POD were also detected acoustically (Koschinski et al. 2003). Moreover, the echolocation rate, i.e. occurrence of click-trains, in our study (mean of 36.8 clicks $\mathrm{min}^{-1}$ ) corresponded well with those ( 0 to 25 clicks $\mathrm{min}^{-1}$ ) reported by Akamatsu et al. (1994) in a 2 wk study of 2 captive porpoises.

It is believed that harbour porpoises use their sonar mainly for navigation and catching their prey (Møhl \& Andersen 1973), but there are no estimates of how frequently free-ranging porpoises use their sonar. It must be emphasised that captive individuals may not use their echolocation as much as wild individuals due to better visual conditions, no need to hunt for food, and well-known surroundings. The angular range of their sonar is rather limited (the $3 \mathrm{~dB}$ transmission beam width is $16^{\circ}$; $\mathrm{Au}$ et al. 1999), suggesting that the recorded echolocation activity may provide an underestimate of the 'true echolocation activity' within the T-POD range of detection, depending on the porpoises' movement patterns.

\section{Harbour porpoise monitoring}

Methods of monitoring harbour porpoises have mainly comprised abundance estimation by means of transect surveys from ship or airplane (Hiby \& Hammond 1989). Estimating population sizes provides an important basis for conservation strategies in relation to the impact of bycatch in gillnet fisheries (Hammond et al. 2002). Surveys may also provide a means for environmental impact studies in localised regions such as (e.g.) offshore wind farms. However, in areas with relatively low harbour porpoise density, as in the SW Baltic Sea, density estimates will have a relatively high variance, which makes it difficult to obtain a reasonable power for statistical testing of a potential impact. Porpoise density estimates were also documented as depending on sea state (Barlow 1988, Palka 1996, Teilmann 2003). Different observers and platforms for the different surveys is another important source of variation that is not usually accounted for. Furthermore, substantial changes in diurnal and seasonal diving patterns (Teilmann et al. 2006b) are likely to bias density estimates obtained from visual surveys.

Acoustic monitoring by means of T-PODs provides high-resolution data in time, but has limited spatial coverage (Koschinski et al. 2003). New insight into seasonal, diurnal and area-specific porpoise occurrence can be obtained from this technique, particularly if the data are combined with covariates (e.g. salinity, currents) hypothesised to influence distribution patterns of harbour porpoises. As yet, echolocation activity has not been, associated with density estimates, rendering this technique less useful for some management tasks. However, based on the present study we believe that echolocation activity can be regarded as a proxy estimate of relative abundance, making the T-POD an important tool for impact assessments in relatively small and defined areas.

\section{Waiting time indicator}

Continuous logging of environmental processes provides a whole new wealth of information, but places considerable demand on data processing. The echolocation activity recorded by the T-POD is a typical point process, similar to (e.g.) precipitation measured by tipping-bucket rain gauges. Although the threshold of 10 min used to separate encounters was determined empirically, this value appears reasonable from a biological point of view also. With an average swimming speed of $1.5 \mathrm{~m} \mathrm{~s}^{-1}$ (Teilmann 2000), a harbour porpoise would move $900 \mathrm{~m}$ in $10 \mathrm{~min}$. With a T-POD detection range of about $170 \mathrm{~m}$ (Koshinski et al. 2003), it thus seems reasonable to use $10 \mathrm{~min}$ for separating encounters to obtain data that, although not entirely independent, are not strongly correlated. However, the autocorrelation suggests that there is still a significant probability that an individual porpoise or group of porpoises are being repeatedly recorded at successive waiting times. The estimated correlation structure shows that, beside the overall seasonal pattern, there are some systematic temporal variations at the scale of hours and days. The correlation between successive waiting times could also be due to non-stationary spatial patchiness in porpoise densities, such that during some periods there is a high density in the entire region leading to many short waiting times, and at other times a low density resulting in a few long waiting times.

The porpoise-click recordings could potentially be aggregated into lower frequency time series, e.g. daily observations, and the BACI analysis carried out using an appropriate transformation and distribution. However, in areas with a generally low density of harbour porpoises, several consecutive days with zero observations might result, and daily observations potentially reflect severe serial correlation. Therefore, the level of temporal aggregation should depend upon the areaspecific porpoise echolocation activity. Encounters and waiting times have the advantage that these data can be combined with short-term disturbances such as 
ramming/vibration activity, whereas it is not possible to detect potential impacts on the time scale of $24 \mathrm{~h}$ or less from daily observations.

\section{Monitoring designs}

The T-POD deployments were planned as a symmetrical design with 3 stations in both the impact and reference areas. The exclusion of data from Stn Ref. $\mathrm{N}$ in combination with data losses from some deployments resulted in an uneven distribution of data over time and space. Applying the waiting time definition to the click-train recordings added to this skewness, with considerably more data in the summer months. Applying a seasonal variation in the BACI analysis allowed comparison of data sampled across different time periods. This asymmetry in both time and space sampling is a modification of the original BACI design (Green 1979), which did not consider several locations, and the 'Beyond BACI' design (Underwood 1994), which considered spatial replication in an asymmetrical design, but with the given process being considered as sampled at the same time at all locations. These designs have successfully been employed in a variety of different impact studies such as sewage outfall construction and removal (Archambault et al. 2001, Bishop et al. 2002), demersal trawling (Schratzberger et al. 2002, Rosenberg et al. 2003) and marine constructions (Lewis et al. 2002).

Another modification of the traditional BACI design was to incorporate a covariance structure for the residuals by means of a stochastic process. The large amount of data enabled consistent estimates of the covariance structure in the different analyses. Attempts to estimate the ARMA (autoregressive moving average) parameters in the analysis of the first and second waiting times after ramming activity were not successful due to convergence problems of the optimisation algorithm. Lack of data could be one reason why temporal correlations are generally ignored in BACI analyses and independent observations are assumed from re-sampling the same location. Another approach to accommodate temporal correlations is the application of repeated-measures designs (Green 1993).

\section{Construction impact}

The present study documents a substantial effect on the harbour porpoise echolocation activity from construction activities in general (medium-term response) and from specific ramming/vibration activities (shortterm response). The data indicate that the porpoises avoided the construction area to a large extent or, alternatively, that their density remained unchanged but that they used their echolocation signals much less due to (e.g.) noise from construction activities. However, Koschinski et al. (2003) found that harbour porpoises used their echolocation more intensively when wind-turbine noise was played back to them in the wild. Teilmann et al. (2006a) found no change in echolocation activity in captive harbour porpoises when various high frequency sounds (100 to $140 \mathrm{kHz}$, $153 \mathrm{~dB}$ re $1 \mu \mathrm{Pa}$ (RMS) at $1 \mathrm{~m}$ ) were played back, except during the first exposure to these relatively loud sounds, when the porpoises almost refrained from echolocating for the full 5 min sound exposure. Based on these experiments, it is unlikely that the harbour porpoises in our impact area would have echolocated less than in the reference area over the entire construction period. We contend that the recorded decrease in echolocation activity was related to a decrease in the density of the harbour porpoises.

The impact of ramming and vibration activity had a substantial, but short-lived effect on harbour porpoise activity at all stations, with significant increases in the first waiting times only. These 2 sources of acoustic disturbance during these construction activities had quite different properties. Frequency range and noise levels associated with the ramming/vibration activity were not measured. Noise from similar pile-driving operations was reported by Würsig et al. (2000), who measured broad-band noise in the frequency range $100 \mathrm{~Hz}$ to $25.6 \mathrm{kHz}$. The maximum octave band noise level measured was $170 \mathrm{~dB}$ re $1 \mu \mathrm{Pa}(400 \mathrm{~Hz}$ centre frequency) $250 \mathrm{~m}$ from the pile-driving site. Assuming pure cylindrical spreading in the shallow water area around the pile-driving site, this corresponds to a source level of approximately $194 \mathrm{~dB}$ re $1 \mu \mathrm{Pa}$.

The harbour porpoise pinger deployed near Foundation A8 in connection with the ramming/vibration activity transmitted 8 different frequency modulated signals in the 20 to $160 \mathrm{kHz}$ frequency bands, with a maximum source level of $145 \mathrm{~dB}$ re $1 \mu \mathrm{Pa}$ (www. aquatec.demon.co.uk). This sound device can be sensed by the harbour porpoises at a maximum range of $1600 \mathrm{~m}$ at Sea State 0 (Teilmann 2000). Given that distances from Foundation A8 to the monitoring stations were at least $2 \mathrm{~km}$, it is unlikely that the harbour porpoise pinger could affect the recorded echolocation activity. The seal scarer used a source level of $189 \mathrm{~dB}$ re $1 \mu \mathrm{Pa}$ in the 10 to $15 \mathrm{kHz}$ range (www.lofitech.no) that may have affected the harbour porpoises over greater distances. Hence, noise from the ramming/vibration activity and the seal scarer were most probably of similar magnitude, but considering that the higher frequencies of this harassment device are attenuated more quickly than the low frequencies of the construction works (Urick 1983), the 
sound level of this activity is likely to be higher in the reference area. However, harbour porpoise responses to different noise frequencies have not yet been documented.

Increases in waiting times were longer (4 to $41 \mathrm{~h}$ ) than the duration of the ramming/vibration activities (1.5 to $10 \mathrm{~h})$, with a tendency of relatively longer first waiting times in the impact area. This indicates that the ramming/vibration activities had a spatially declining effect on harbour porpoise densities, extending most probably beyond the 3 stations in the reference area (located $>15 \mathrm{~km}$ from Foundation A8). If the porpoises were affected by noise from the construction over such long distances, this could explain that the first waiting times at the reference stations increased by several hours. Furthermore, if the reference stations were affected by the specific ramming/vibration activity, it is also likely that other construction activities may have influenced their density in the reference area. Although the BACI analysis assumed the reference area to be unaffected by the construction activities, the doubling of the waiting times in this area (Table 4) could potentially be associated with the construction of the wind farm. This implies that waiting times in the impact area may have increased by more than a factor of 6 . Although we have established empirical evidence that construction activities reduced the echolocation activity of harbour porpoises in this study, and most probably reduced porpoise density also, the underlying cause-effect mechanisms still need to be investigated. Future years of monitoring will show if the harbour porpoise population in the Nysted Offshore Wind Farm region will recover.

The development of offshore activities is increasing rapidly, giving rise to a demand to assess their effect on the marine environment. The method developed in this study may be modified to study other echolocating cetaceans and determine the potential effect from offshore constructions or other human activities within a specified area.

Acknowledgements. We are grateful to Gregers Glendorf, Svend-Erik Rasmussen and Jan Simonsen from the cutter MS 'Amigo' for help with the T-POD deployments and their invaluable expertise on offshore equipment. We thank our colleagues Susi Edrén and Thomas Dau Rasmussen for help in the field, Ib Krag Petersen for providing the map, and Jakob Tougaard for constructive discussions on the acoustics. Nick Tregenza (Chelonia) is acknowledged for kind and prompt responses related to the T-PODs. We thank Charlotte Boesen, Per Hjelmsted Pedersen, Hans Ohrt and Pernille Holm Skyt from Energi E2 A/S for valuable comments on the manuscript and providing all necessary information and support in relation to the construction work. These investigations were funded by Danish public service obligations under contract with Energi E2 A/S. The manuscript was improved by valuable comments by anonymous reviewers.

\section{LITERATURE CITED}

Akamatsu T, Hatakeyama Y, Kojima T, Soeda H (1994) Echolocation rates of 2 harbor porpoises (Phocoena phocoena). Mar Mamm Sci 10:401-411

Archambault P, Banwell K, Underwood AJ (2001) Temporal variation in the structure of intertidal assemblages following the removal of sewage. Mar Ecol Prog Ser 222:51-62

$\mathrm{Au}$ WWL, Kastelein RA, Rippe T, Schooneman NM (1999) Transmission beam pattern and echolocation signals of a harbour porpoise (Phocoena phocoena). J Acoust Soc Am 106:3699-3705

Au WWL, Ford JKB, Horne JK, Allman KAN (2004) Echolocation signals of free-ranging killer whales (Orcinus orca) and modeling of foraging for chinook salmon (Oncorhynchus tshawytscha). J Acoust Soc Am 115:901-909

Bach S, Teilmann J, Henriksen OD (2000) Environmental impact assessment (EIA) of offshore wind farms at Rødsand and Omø Stålgrunde, Denmark. Virum, Rambøll (also available at: www.nystedhavmoellepark.dk/upload/pdf/ Ramboll_2_Pebr.pdf)

Barlow J (1988) Harbor porpoise, Phocoena phocoena, abundance estimation for California, Oregon and Washington. I. Ship surveys. Fish Bull (Seattle) 86:417-432

Bishop MJ, Underwood AJ, Archambault P (2002) Sewage and environmental impacts on rocky shores: necessity of identifying relevant spatial scales. Mar Ecol Prog Ser 236: 121-128

Chatfield C (1984) The analysis of time series - an introduction, 3rd edn. Chapman \& Hall, London

Cox TM, Read AJ, Solow A, Tregenza N (2001) Will harbour porpoises (Phocoena phocoena) habituate to pingers? J Cetacean Res Manag 3:81-86

Culik BM, Koshinski S, Tregenza N, Graeme ME (2001) Reactions of harbor porpoises (Phocoena phocoena) and herring (Clupea harengus) to acoustic alarms. Mar Ecol Prog Ser 211:255-260

Green RH (1979) Sampling design and statistical methods for environmental biologists. Wiley, New York

Green RH (1993) Application of repeated-measures designs in environmental-impact and monitoring studies. Aust J Ecol 18:81-98

Hammond P, Benke H, Berggren P, Borchers DL and 7 others (2002) Abundance of harbour porpoises and other cetaceans in the North Sea and adjacent waters. J Appl Ecol 39:361-376

Heide-Jørgensen M, Mosbech A, Teilmann J, Benke $\mathrm{H}$, Schultz W (1992) Harbour porpoise (Phocoena phocoena) densities obtained from aerial surveys north of Fyn and in the Bay of Kiel. Ophelia 35:133-146

Heide-Jørgensen M, Teilmann J, Benke H, Wulf J (1993) Abundance and distribution of harbour porpoises, Phocoena phocoena, in selected areas of the western Baltic and the North Sea. Helgol Meeresunters 47:335-346

Hiby AR, Hammond PS (1989) Survey techniques for estimating abundance of cetaceans. Rep Int Whal Comm Spec Issue 11:47-80

Koschinski S (2002) Current knowledge on the harbour porpoises (Phocoena phocoena) in the Baltic Sea. Ophelia 55: 167-197

Koschinski S, Culik B, Henriksen OD, Tregrenza N, Ellis G, Jansen C, Kathe G (2003) Behavioural reactions of freeranging porpoises and seals to the noise of a simulated 2 MW windpower generator. Mar Ecol Prog Ser 265: 263-273

Lewis LJ, Davenport J, Kelly TC (2002) A study of the impact of a pipeline construction on estuarine benthic inver- 
tebrate communities. Estuar Coast Shelf Sci 55:213-221

Littell RC, Milliken GA, Stroup WW, Wolfinger RD (1996) SAS system for mixed models. SAS Institute, Cary, NC

McCullagh P, Nelder JA (1989) Generalized linear models, 2nd edn. Monographs on statistics and applied probability, 37. Chapman \& Hall/CRC, Boca Raton, FL

McCulloch CE, Searle SR (2001) Generalized, linear, and mixed models. Wiley series in probability and statistics. Wiley, New York

Møhl B, Andersen S (1973) Echolocation: high-frequency component in the click of the harbour porpoise (Phocoena ph. L.). J Acoust Soc Am 54:1368-1373

Palka D (1996) Effects of Beaufort sea state on the sightability of harbor porpoises in the Gulf of Maine. Rep Int Whal Comm 46:575-582

Rosenberg R, Nilsson HC, Gremare A, Amouroux JM (2003) Effects of demersal trawling on marine sedimentary habitats analysed by sediment profile imagery. J Exp Mar Biol Ecol 285:465-477

Schratzberger M, Dinmore TA, Jennings S (2002) Impacts of trawling on the diversity, biomass and structure of meiofauna assemblages. Mar Biol 140:83-93

Teilmann J (2000) The behaviour and sensory abilities of harbour porpoises (Phocoena phocoena) in relation to bycatch in gillnet fishery. $\mathrm{PhD}$ thesis, University of Southern Denmark, Odense

Teilmann J (2003) Influence of sea state on density estimates of harbour porpoises (Phocoena phocoena). J Cetacean Res Manag 5:85-92

Teilmann J, Henriksen OD, Carstensen J, Skov H (2002) Mon-

Editorial responsibility: Howard I. Browman (Associate

Editor-in-Chief), Storebø, Norway itoring effects of offshore wind farms on harbour porpoises using PODs (porpoise detectors). Tech Rep. National Environmental Research Institute, Roskilde (also available at: http://www.hornsrev.dk/Engelsk/default_ie.htm)

Teilmann J, Dietz R, Larsen F, Desportes G and 5 others (2004) Satellitsporing af marsvin i danske og tilstødende farvande. Tech Rep. National Environmental Research Institute, Denmark, Roskilde. (In Danish with English summary.) (Also available at: http://www2.dmu.dk/1_viden/2_ Publikationer/3_fagrapporter/rapporter/FR484_samlet.pdf)

Teilmann J, Tougaard J, Miller L, Kirketerp T, Hansen K, Labberté S (2006a) Reaction of captive harbour porpoises (Phocoena phocoena) to pinger-like sounds. Mar Mamm Sci 22:240-260

Teilmann J, Larsen F, Desportes G (2006b) Time allocation and diving behaviour of harbour porpoises (Phocoena phocoena) in Danish and adjacent waters. J Cetacean Res Manag (in press)

Thomsen F, van Elk N, Brock V, Piper W (2005) On the performance of automated porpoise-click-detectors in experiments with captive harbor porpoises (Phocoena phocoena) (L). J Acoust Soc Am 118:37-40

Underwood AJ (1994) On beyond BACI: sampling designs that might reliably detect environmental disturbances. Ecol Appl 4:3-15

Urick RJ (1983) Principles of underwater sound. McGrawHill, New York

Würsig B, Greene CR Jr, Jefferson TA (2000) Development of an air bubble curtain to reduce underwater noise of percussive piling. Mar Environ Res 49:79-93

Submitted: July 14, 2004; Accepted: January 21, 2006

Proofs received from author(s): August 16, 2006 